\title{
DESIGN AND IMPLEMENTATION OF AUTOMATED PRICING SYSTEM USING PHP \& MYSQL
}

\author{
Ajiteru S.O ${ }^{1}$, Iromini N.A ${ }^{2}$ and Oluwasogo S.A ${ }^{1}$ \\ ${ }^{1}$ ICT Centre, Federal Polytechnic Offa, Offa, Kwara State,Nigeria. \\ ${ }^{2}$ Department of Computer Engineering, Federal Polytechnic Offa, Offa, Kwara State, Nigeria \\ yemiajiteru@yahoo.com, ajibolaforyu2003@yahoo.com, samueloluwasogo@gmail.com
}

DOI: $10.31364 / \mathrm{SCIRJ} / \mathrm{v} 8.13 .2020 . P 0320756$

http://dx.doi.org/10.31364/SCIRJ/v8.i3.2020.P0320756

\begin{abstract}
This paper focuses on the design and implementation of an automated pricing system using international breweries Ilesha as a case study. The research makes a provision for the customization of the program designs in order to accommodate other manufacturing company such as Cadbury, Unilever, Nigeria breweries, Nestle etc. The objectives include reduction of stress, paper work and error, also to increase speed and satisfy customers. The research work proffer a solution to a competitive price changes and assists enterprise on how to quickly respond to price change. This gives rooms for easy \& quick price adjustment. In order to achieve all these, design and implementation of an automated pricing system is necessary. This paper presents the design of a web based application called Price Engine by making use of PHP, MySQL, Apache, Dreamweaver, and HTML as design tools.
\end{abstract}

Index Terms: Automation, price system, design, database, form, PHP \& MySQL

\section{INTRODUCTION}

This paper is concerned with the design of an automated pricing system that will help the consumers, retailers, marketers, distributors in making urgent and perfect decision. The recent rapid implementation of Information and communication technology in all areas of life has really transformed the nature and quality of work being carried out.

(Alagheband, 2007) Application of new communications and information technologies has created significant changes in products, activities and life of people. Communications and information technologies quickly change social structure and lifestyles of people around the world and affect significantly on their performance.

(Dalvez, 2001, page22) Facts show that using new technologies in 21 century will affect deeply on social life of human and certainly education will meet these changes. Research conducted in education show that information technology has been used mainly in regular education system. (Amiri, 1990) Today, automation and application of new technologies is not only considered as a need but as a critical necessity.

Zuboff (1988) describes this dichotomy as the ability of information technology to informate or automate the workplace. The capacity of information technology to generate vast amounts of infor-mation about the underlying processes of production and administration, allows employers to infor-mate their work force so that employees can do their jobs better.

PRICING SYSTEM: Pricing system is a system for setting prices on good or services. A price system in economics serves the function of regulating the production and consumption of goods by determining their monetary or trade value. 
The needs to use information and communication technology to improve services, lower cost and become more competitive has drawn our attention to contribute in order to break free of the cumbersome pricing system by designing and implement a new system that will make work processes faster, easier and make it respond to market changes more quickly.

The significance of this paper is to reduce error, stress and saves time. Under manual system, changing pricing on every product each month or quarter normally take over three months and is error prone. Performing the quarterly pricing required calculating new prices, review them, printing them, review them again and feeding them into computer system. After that, the new price lists would be mailed, faxed \& sent to trading partners \& regional sales representatives, this is cumbersome and there is a need to design a centralized database using mysql database and query report using php scripting language and make it accessible online via web browsers.

The scope of the paper covers calculating new prices, editing and deriving, updating new prices and making the price list available to trading partners and regional sales representatives in a real time (i.e online) by accessing a centralized database for quick reference.

\section{AIMS AND OBJECTIVES OF THE STUDY}

The general aim of the research work shall be to proffer a solution to a competitive price change and assist enterprise on how to quickly respond to this prices change. This will give rooms for easy \& quick price adjustment. To this end, the objectives of the research work shall be:

1. To design an automated pricing system

2. To reduce stress.

3. To reduce paper work.

4. To satisfy customers

5. To reduce error.

\section{RESEARCH METHOLODOLOGY}

This paper uses statistical method of transcription from records to gather information about the pricing system. Observation method was also used to study the manual process currently in place. The design is carried out using Open Source technology such as PHP, Mysql, Apache and Dreamweaver to design and implement a price engine

\section{HISTORICAL BACKGROUND OF INTERNATIONAL BREWERIES}

International Breweries Plc was incorporated in December 1971 by its founder and first Chairman, Dr. Lawrence Omole in collaboration with some of his business associates, under the name International Breweries Limited. To date, the Company's products are TROPHY lager beer, CASTLE, CASTLE MILK, GRAND MALT and BETA MALT, a nonalcoholic beverage drink which came into production in 1988 .

\section{CODING}

The "PriceEngine" is designed with Dreamweaver, fireworks, HTML and CSS, coded with PHP and uses MYSQL as backend database. The web server used is Apache. Therefore, for this project to work properly both offline and online the project folder named "PriceEngine" must be in htdocs folder of Apache folder inside C drive. It must also be of interest that while trying to upload files to the web host server, the database and all the table needs to be recreated or better still be exported to the server. After all these must have been implemented, the application will be up and running. 
"PriceEngine" has a starting page called the index page. When you open a browser and type the ip address or the domain name of the machine hosting "PriceEngine" the first page you will see is the index page, the user will then navigate to the sign in or log in page which serves as a check for users.

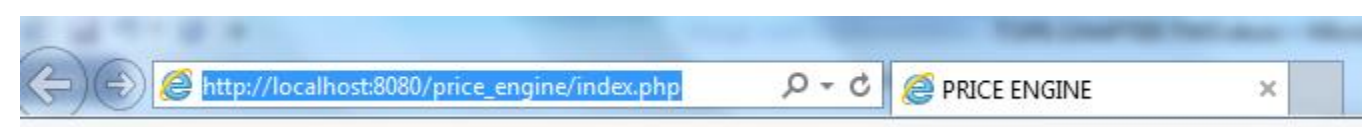

Figure 1:- The Url address/IP address

AUTHENTICATION CENTRE: The user has to supply the username and password given to him or her by the administrator at the Authentication Centre.

MAIN PAGE : After the authentication, "PriceEngine" takes the user to the main page which serves as a starting point for the rest of the pages. The main page is as shown below.

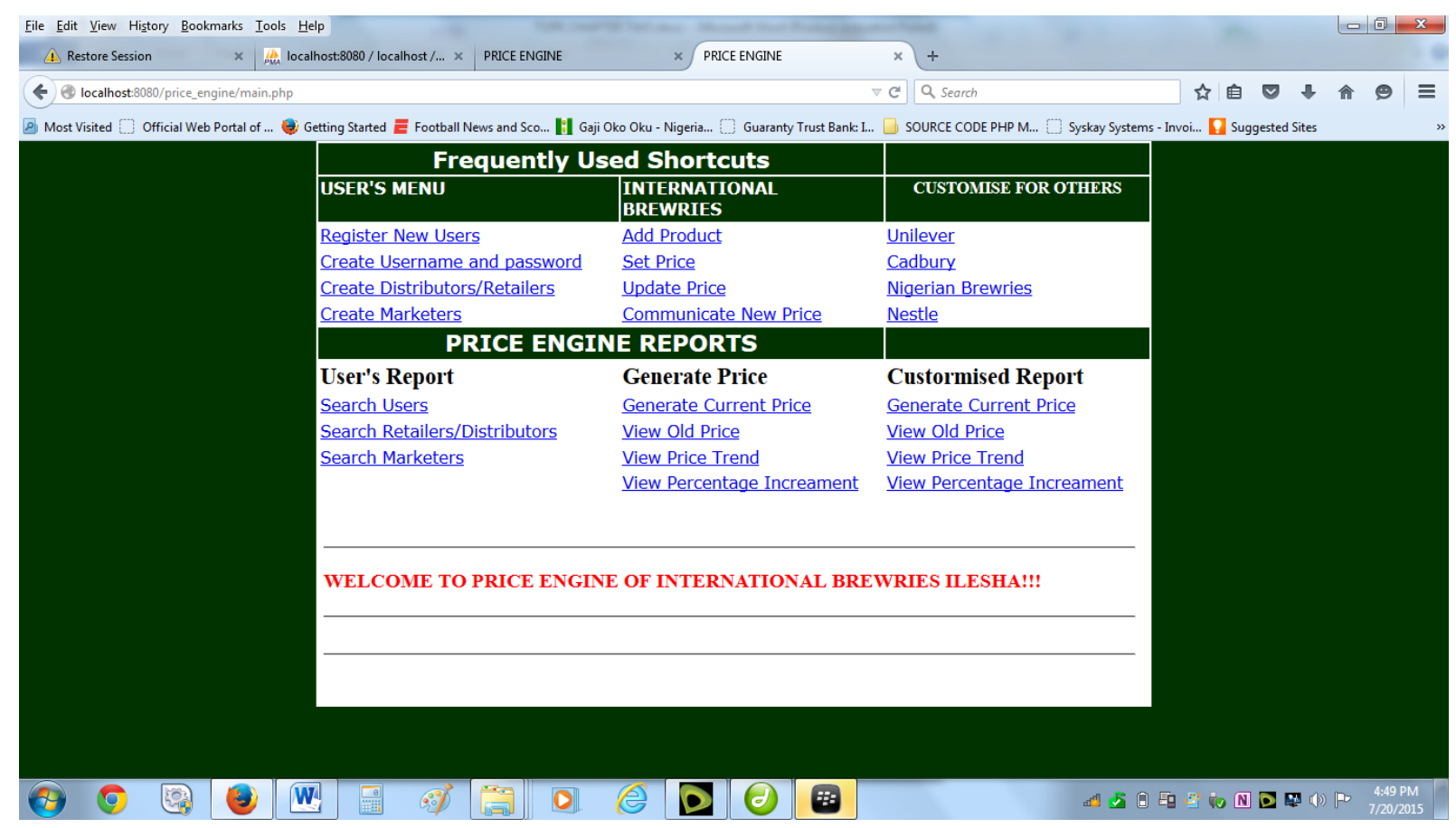

Figure 2: The Main Page

INPUT DESIGN: The input design considers the data items needed to update the database. This will be done by the in-house users based on their departmental data.

SETTING NEW PRICE: To set new price for the new product the form below in figure 3 is used i.e "Set New Price for a New Product Form". The following form fields are gathered to update the database: Product Name, Product Category, Product Description, Starting Price, Starting Date, Current Price, Current Date, Percentage (increment) 


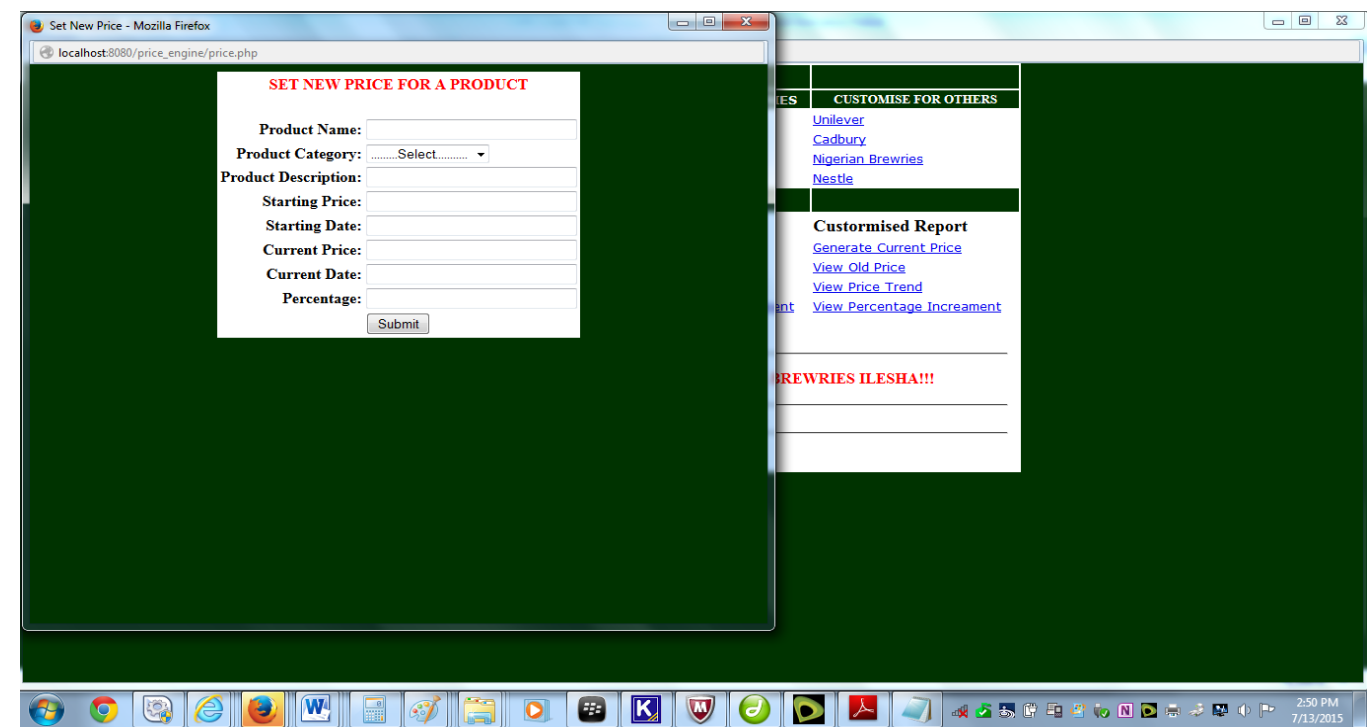

Figure 3: Input Form to set the percentage change in price

For every new product, the "set new price form" must be used to set the price and gather some details about the new product as shown above. Then the "update form" would be used subsequently to update any change in price. The update form is as shown below in figure 4.

What needed to be updated subsequently is the percentage change in price, current date and current price so that PriceEngine can generate the new price.

In order to update the price list a user needs to click on "Update Price" link on the main page, a search form will come up where the user will supply the product id in order to search for a particular product to be updated.

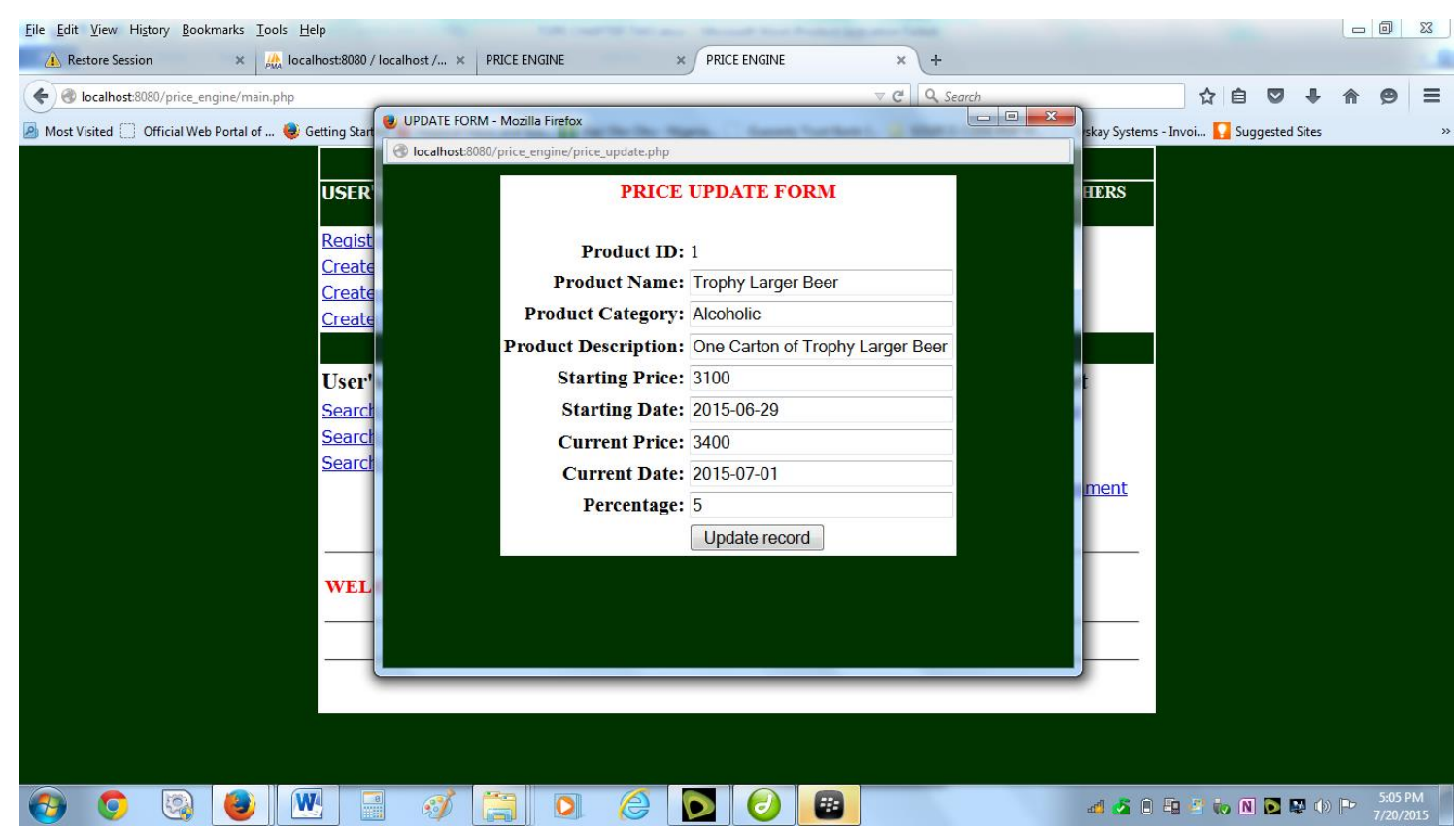

\section{Figure 4: Update Form}


OUTPUT DESIGN: The output design contains additional information compare to the input design. All data from the input source after processing constitute the output.

\section{PriceEngine Design}

This is the main engine designed to generate the price list. The user would click on the "Generate Price List" on the main page, this will show the main engine that generate price list as shown below in Figure 5.

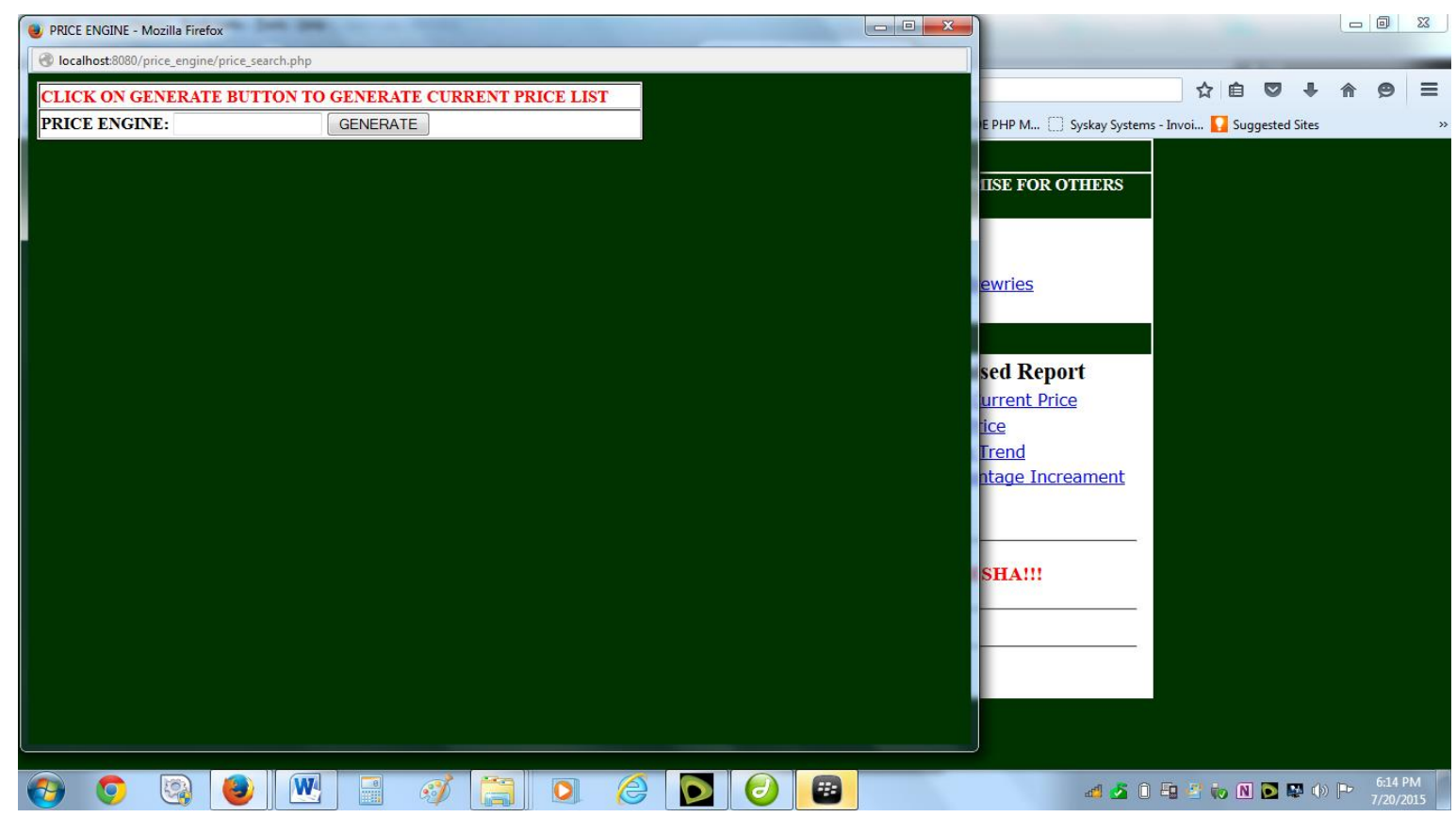

\section{Figure 5:- PriceEngine: The main Engine that Generate Price List}

\section{Generated Price List}

Figure 6 below shows the generated pricelist which can be printed, accessed online, or sent via email and SMS. 


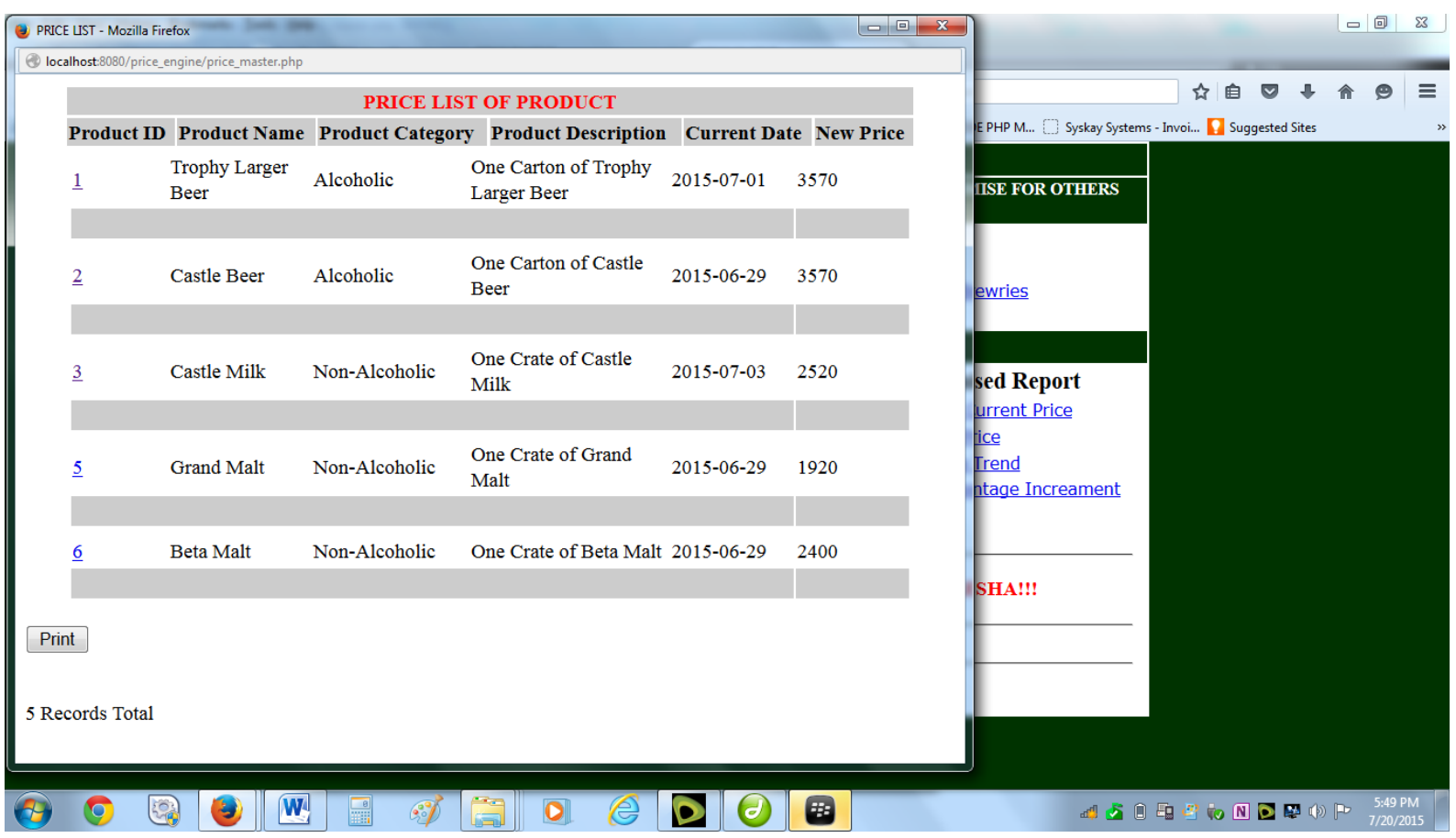

Figure 6:- Master Price List

\section{CONCLUSION}

Manual operations in divers form in many organization and societies have posed a great problem in terms of accuracy, efficiency, and effectiveness just to mention a few. In view of these defects, the only solution to this problem is by developing an automated or computerized system that make use of powerful and effective software to process and retrieve data at a high speed.

\section{RECOMMENDATION}

In order to cut cost and make job of getting new price across border easier, it is therefore recommended that this research work should be embraced by manufacturers, distributors, retailers etc. The PriceEngine has been designed in such a way that it could serve as a prototype for developing a larger automated package. Finally, training is recommended before total system conversion.

\section{REFERENCES}

Alagheband, (2007). Theoretical principles and education management. Besat publication in Persian, 4th edition.

Amiri, M., (1990). Thought About Future Changes in Education. Tehran: Madreseh publications in Persian.

Bergen, C. (1988). "Instruments to plague us? - Human factors in the management of library auto-mation," Library Management, 9 (6): 3-55.

Dakshinamurti, G. (December 1985). "Automation's effect on library personnel," Canadian Library Journal, pp. 343-351.

Dalvez(2001). Education for 21 Century, Translated by Eftekharzadeh, Seyed Farhad. Tehran: Abed publication in Persian.

Forester, T. (April 18, 1989). "Automation: for better or worse?" The Australian, pp. 44-45.

Freedman, M. J. (June 15, 1984). "Automation and the future of technical services," Library Journal, pp. 1197-1203. 
Harris, C. L. (1989). "Office automation: making it pay off," In Computers in the human contex, edited by T. Forester. Oxford: Basil Blackwell. pp. 367-376.

Horny, K. L. (http://www.britannica.com/EBchecked/topic/475822/price-system Date Accessed: 02/05/2015

\section{http://en.wikipedia.org/wiki/Price system Date Accessed: 02/05/2015}

http://www.answers.com/Q/What_are_the_advantages_and_disadvantages_of_the_price_system Date Accessed: 02/05/2015

International Journal of Academic Research in Business and Social Sciences September 2013, Vol. 3, No. 9 ISSN: 2222-6990379 www.hrmars.com/journals

Jones, D. E. (Spring 1989) "Library support staff and technology: perceptions and opinions," Library Trends, 37 (4): $32-56$.

Kazemi Motafa \& Arjmandinezhad Afagh \& Eftekhar,( 0331).” Considering inter organizational

Kraske, G. (1979). The impact of automation on the staff and organization of a medium-sized academic library: A case study. Indiana: Indiana University.

Long, R. J. (1989). "Human issues in new office technology," In Computers in the human contex, edited by T. Forester. Oxford: Basil Blackwell. pp. 327-334.

Mohammad, H.M.J, Hajar .S (September 2013) Assessing Office Automation Effect on Performance Using Balanced Scorecard approach Case Study: Esfahan Education Organizations and Schools International Journal of Academic Research in Business and Social Sciences September 2013, Vol. 3, No. 9 ISSN: 2222-6990

Zuboff, S. (1988). In the age of the smart machine: The future of work and power. Oxford, Heinemann Professional.

Zuboff, S. (Autumn 1985). "Automate/Informate: the two faces of intelligent technology," Organi-zational Dynamics, 14 (2: 5-18. 